\title{
Production of Genistein in Amaranthus tricolor var. tristis and Spinacia oleracea by Expression of Glycine max Isoflavone Synthase
}

\author{
Ashwini Malla ${ }^{1,+}\left(\mathbb{D}\right.$, Balamurugan Shanmugaraj ${ }^{1,+}$, Ashutosh Sharma ${ }^{2, *} \mathbb{D}$ and Sathishkumar Ramalingam $1, * \mathbb{C}$ \\ 1 Plant Genetic Engineering Laboratory, Department of Biotechnology, Bharathiar University, \\ Coimbatore 641 046, India; malla164_ashwini@yahoo.co.in (A.M.); balagene3030@gmail.com (B.S.) \\ 2 Tecnologico de Monterrey, School of Engineering and Sciences, Centre of Bioengineering, Campus Queretaro, \\ Av. Epigmenio González No. 500, Fracc. San Pablo, Queretaro 76130, Mexico \\ * Correspondence: asharma@tec.mx (A.S.); rsathish@buc.edu.in (S.R.); Tel.: +91-9360151669 (S.R.) \\ + Both the authors are equally contributed.
}

check for updates

Citation: Malla, A.; Shanmugaraj, B.; Sharma, A.; Ramalingam, S.

Production of Genistein in

Amaranthus tricolor var. tristis and Spinacia oleracea by Expression of Glycine max Isoflavone Synthase. Plants 2021, 10, 2311. https://doi.org/ $10.3390 /$ plants10112311

Academic Editor: Manuel Viuda Martos

Received: 6 September 2021

Accepted: 8 October 2021

Published: 27 October 2021

Publisher's Note: MDPI stays neutral with regard to jurisdictional claims in published maps and institutional affiliations.

Copyright: (C) 2021 by the authors. Licensee MDPI, Basel, Switzerland. This article is an open access article distributed under the terms and conditions of the Creative Commons Attribution (CC BY) license (https:/ / creativecommons.org/licenses/by/ $4.0 /)$.
Abstract: Isoflavonoids, the diverse group of secondary metabolites derived from the phenylpropanoid pathway, are distributed predominantly in leguminous plants. It has received considerable attention in recent days due to its health promoting benefits and is known to prevent certain diseases in humans. These isoflavonoids are synthesized from flavonoid intermediates of phenylpropanoid pathway by the enzyme isoflavone synthase. Metabolic engineering of isoflavonoid biosynthesis in non-legume crop plants could offer the health benefits of these compounds in diverse plant species further contributing for crop improvement. The transient expression of heterologous genes in the host is considered as an alternative to stable expression, that can provide a rapid way of studying the pathway engineering for metabolite production and could also act as a production platform for nutraceuticals and biopharmaceuticals. In this study, isoflavone genistein was produced in Amaranthus tricolor var. tristis and Spinacia oleracea by transiently expressing Glycine max isoflavone synthase (GmIFS). The GmIFS gene was cloned in plant expression vector pEarleyGate 102 HA and pEAQ-HT-DEST 3 and transformed into plants by agroinfiltration. The presence of transgene in the agroinfiltrated leaves was confirmed by semiquantitative reverse-transcription polymerase chain reaction. The flavonoid substrate naringenin and isoflavonoid genistein were quantified using high performance liquid chromatography in both wild-type and infiltrated leaf samples of both the plants. The naringenin content varied in the range of $65.5-338.5 \mathrm{nM} / \mathrm{g}$ fresh weight, while the accumulation of genistein was observed with varying concentrations from 113 to $182.6 \mathrm{nM} / \mathrm{g}$ fresh weight in the agroinfiltrated leaf samples of both A. tricolor var. tristis and S. oleracea. These results indicate that the transient expression of GmIFS gene has led to the synthesis of isoflavonoid genistein in A. tricolor var. tristis and S. oleracea providing an insight that stable expression of this gene could enrich the nutraceutical content in the crop plants. To the best of our knowledge, this is the first report on transient expression of GmIFS gene for the production of genistein in A. tricolor var. tristis and S. oleracea.

Keywords: agroinfiltration; Amaranthus tricolor var. tristis; genistein; isoflavone synthase; metabolic engineering; Spinacia oleracea; transient expression

\section{Introduction}

Isoflavonoids, a class of natural plant polyphenols attribute to many biological activities such as antioxidant [1], antimutagenic [2], anticarcinogenic [3-5], antiproliferative [6,7] effects are playing an imperative role in human health and nutrition [8-10]. These compounds are naturally present in Papilionoideae, a subfamily of Leguminosae or Fabaceae members [11]. Apart from the other vital bioactivities, it is evident that the isoflavonoid genistein in dietary consumption showed a wide spectrum of health protective abilities such 
as reducing the risk of cardiovascular problems [12], chronic diseases [13], diabetes [14-16], cancer [3], osteoporosis [12,14-16], obesity [17] and relief from menopausal symptoms [9]. The key enzyme involved in the biosynthesis of isoflavonoids from flavonoid substrates, in the branch of phenylpropanoid pathway, is isoflavone synthase (IFS) (Figure 1), which is natively found in leguminous plants [8,18-21].

The production of high-value recombinant proteins or nutraceuticals in plants either involves the introduction of new gene into the host species or the overexpression of existing ones in the endogenous pathways. The expression methods used for producing target proteins and metabolites in plants can be either stable or transient expression. Predominantly, the gene manipulation in plants has depended on developing stable transgenic lines for heterologous gene expression. However, it involves tedious laborious and time consuming procedures with requirement of enormous resources. The routine and well-established Agrobacterium tumefaciens-mediated gene transfer in plants involves the incorporation of a desired segment of DNA in the binary vector systems and transferred into the plant nuclear genome [22,23]. The recent advances in the transient expression system in plants has led to the remarkable clinches in the scope for producing recombinant proteins, secondary metabolites and other bioactive compounds within a short time in a cost-effective manner [24-27]. The transient approach of gene expression offers a unique potentiality in the production of foreign proteins at rapid speed with intrinsic scalability $[28,29]$. The transient expression by agroinfiltration is a mostly preferred method which can be performed either by syringe infiltration or vacuum infiltration [30]. The genus Nicotiana is commonly used as an efficient host for transient expression of recombinant proteins due to its higher growth rate, biomass, larger leaf surface area and intrinsic cell architecture that supports the protein processing and compartmentalization [27,31,32]. Further, the transient system has also been used to study gene function and gene silencing, as the process is relatively simple and easy to perform [33].

Green leafy vegetables are regarded as 'natures antiaging wonders' due to its medicinal properties [34], nutraceutical values [35] and antioxidant activities [36-38] that form the basic needs of mankind and a prerequisite for healthy life. Green leafy vegetables are the major components in traditional diet due to their health benefits, which are mainly due to the rich source of vitamins, fiber, minerals, micronutrients, macronutrients and various phytochemicals [39] with potential antioxidant properties [40,41]. Amaranthus tricolor var. tristis [42,43] and Spinacia oleracea [44] from Amaranthaceae family are used in this study due to the repositories of bioactive compounds with medicinal value, which are known to prevent human diseases, exerting natural biological properties [34].

In this study, an attempt was made to use the green leafy vegetables such as A.tricolor var. tristis and S. oleracea to demonstrate the production of genistein by transient expression of GmIFS. Toward this, the GmIFS gene was cloned into plant expression vector pEarleyGate 102 HA [45] and pEAQ-HT-DEST 3 [46] and transformed into the plants by agroinfiltration. The infiltrated leaves were harvested, and the metabolites were quantified. The results showed that the transient expression of GmIFS can produce isoflavone genistein from the naringenin intermediate in these leafy vegetables. 


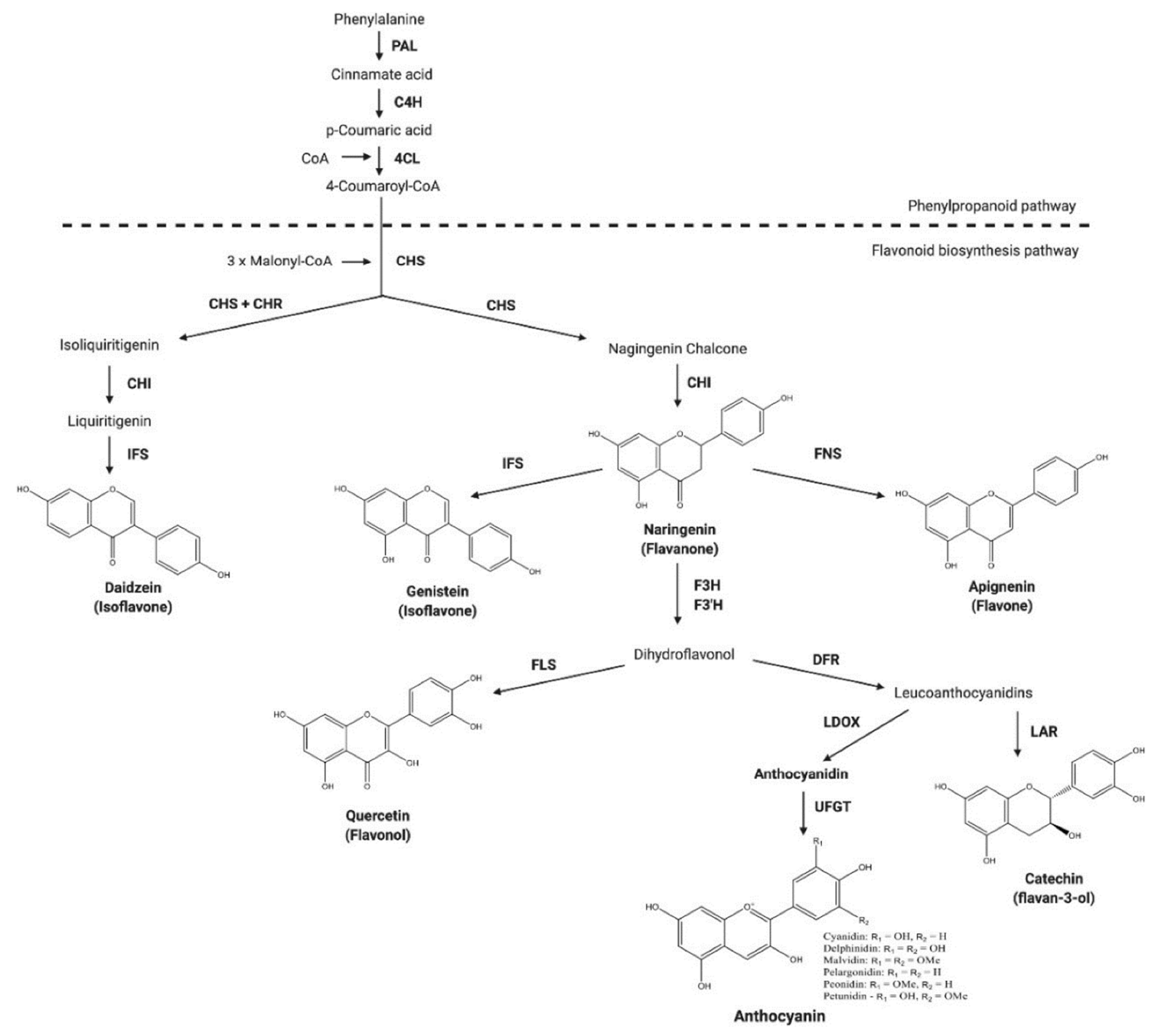

Figure 1. Generalized flavonoid biosynthetic pathway showing the production of genistein from naringenin intermediate. PAL: phenylalanine ammonia-lyase; C4H: cinnamate 4-hydroxylase; 4CL: 4-coumarate-CoA ligase; CHS: chalcone synthase; CHR: chalcone reductase; CHI: chalcone isomerase; IFS: isoflavone synthase; FNS: flavone synthase; FLS: flavonol synthase; F3H: flavanone 3-hydroxylase; F3'H: flavanone 3'-hydroxylase; DFR: dihydroflavonol 4-reductase; LDOX: leucoanthocyanidin dioxygenase; UFGT: UDP-glucose: flavonoid-3-O-glycosyltransferase; and LAR: leucoanthocyanidin reductase (adapted from Ku et al., 2020) [47].

\section{Results}

The seeds of A. tricolor var. tristis and S. oleracea procured from Tamil Nadu Agricultural University seed center were sown in commercially available soil manure mixture for germination and kept in greenhouse. The germinated 15-day-old plantlets were transferred individually to the pots and used for further studies. The schematic representation and timeline for the production of secondary metabolites in plants by transient gene expression are depicted in Figure 2.

\subsection{Confirmation of Cloned IFS in Plant Expression Vector}

The IFS gene procured from Donald Danforth Plant Science Center was used as template to clone the gene in plant expression vector pEarleyGate 102 HA (Figure 3A) and pEAQHT-DEST 3 (Figure 3B) by gateway cloning. Both the vectors were used for the transient expression of IFS gene. The IFS gene was cloned into entry vector $\mathrm{pDONR} /$ Zeo and further moved into the destination vector pEarleyGate $102 \mathrm{HA}$ and pEAQ-HT-DEST 3. The generated clones were confirmed by polymerase chain reaction (PCR) and restriction digestion. 


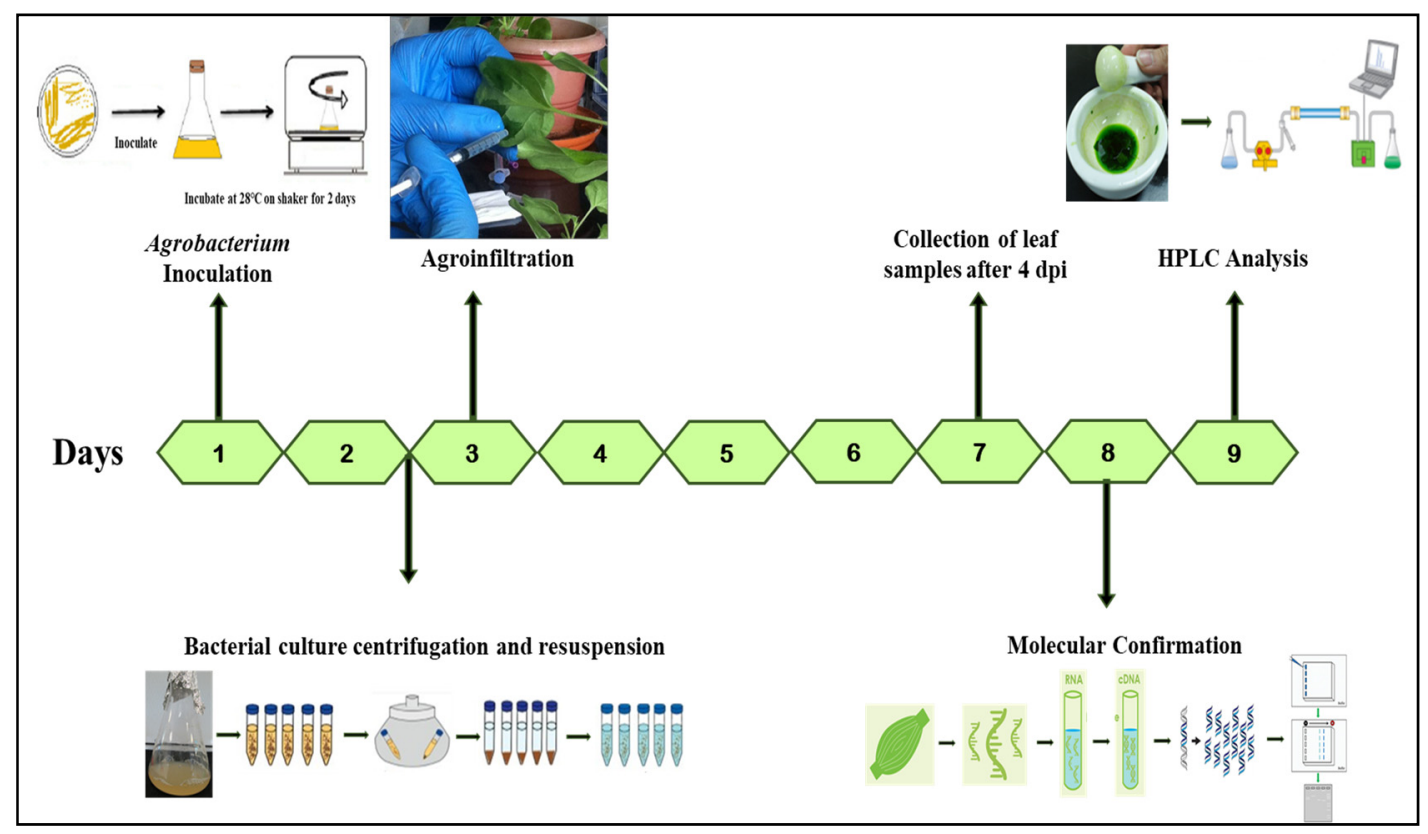

Figure 2. Timeline and diagrammatic representation showing the production of secondary metabolites in plants by transient gene expression.

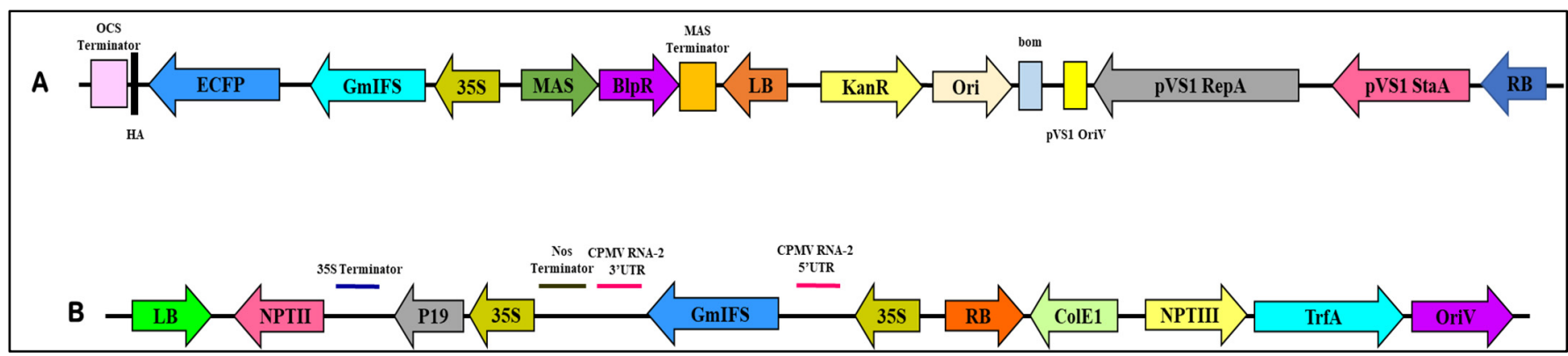

Figure 3. Diagrammatic representation of the gateway destination vectors (A) pEarleyGate102 HA and (B) pEAQ-HT-DEST 3 used in the study. (A) LB and RB: The right and left borders of the T-DNA region in Agrobacterium; MAS terminator: mannopine synthase terminator sequence; BlpR: confers resistance to bialophos or phosphinothricin; MAS: mannopine synthase promoter; 35S: cauliflower mosaic virus 35S promoter; GmIFS: Glycine max L. isoflavone synthase gene; ECFP: enhanced cyan fluorescent protein; HA: human influenza hemagglutinin epitope tag; OCS terminator: octopine synthase terminator; pVS1 StaA: stability protein from Pseudomonas plasmid pVS1; pVS1 RepA: replication protein from Pseudomonas plasmid pVS1; pVS1 OriV: origin of replication for the Pseudomonas plasmid; bom: basis of mobility region from pBR322; Ori: origin of replication; and KanR: confers resistance to kanamycin. (B) LB and RB: The right and left borders of the T-DNA region in Agrobacterium; 35S: cauliflower mosaic virus (CaMV) 35S promoter; P19: the RNA silencing suppressor from tomato bushy stunt virus (TBSV); CPMV RNA-2 5'UTR: $5^{\prime}$ untranslated region from RNA-2 polyprotein of Cowpea mosaic virus (CPMV); CPMV RNA-2 3'UTR: $3^{\prime}$ untranslated region from RNA-2 polyprotein of Cowpea mosaic virus (CPMV); GmIFS: Isoflavone synthase gene from Glycine max L.; OriV: replication origin; ColE1: pBR322 replication origin; TrfA: Replication essential locus; NPT: neomycin phosphotransferase gene conferring resistance to kanamycin; and Nos: nopaline synthase terminator sequence.

\subsection{Transformation of Agrobacterium tumefaciens with GmIFS and Plant Transformation}

Plant expression vector pEarleyGate 102 HA and pEAQ-HT-DEST 3 harboring IFS gene was mobilized into A. tumefaciens AGL1 by electroporation. Electroporation uses short high-voltage pulses which help to beat the capacitance of the cell membrane inducing reversible breakdown of the membrane. This transient, permeabilized state of the membrane allows the passage way of the DNA into the cell [48]. After electroporation, the transformed A. tumefaciens colonies were selected on yeast extract and nutrient broth 
agar plates supplemented with $75 \mathrm{mg} \mathrm{L}^{-1}$ kanamycin and $60 \mathrm{mg} \mathrm{L}^{-1}$ rifampicin, and the colonies were confirmed by PCR using gene specific primers. Positive clone was further subcultured and used for the agroinfiltration.

We set out to investigate the effect of IFS expression in A. tricolor var. tristis and S. oleracea by transient expression using agroinfiltration. Leaves of four-week-old $A$. tricolor var. tristis and S. oleracea (Figure $4 \mathrm{~A}, \mathrm{~B}$ ) were infiltrated with $A$. tumefaciens suspensions containing either one of the vectors pEarleyGate 102 HA or pEAQ-HT-DEST 3 harboring IFS gene (Figure 5). The infiltrated leaves were harvested at day 4 after infiltration. Total RNA was isolated, and cDNA was synthesized, which was used as the template for the semiquantitative reverse-transcriptase PCR. The expected band size of $1500 \mathrm{bp}$ confirmed the expression of IFS gene in the infiltrated leaves of A. tricolor var. tristis and S. oleracea (Figure 6A). The results showed that transcription of the IFS gene was similar in the leaves infiltrated either with pEAQ-HT-DEST 3:IFS or pEarleyGate 102 HA:IFS. $\beta$-Actin ( 114 bp) was used as an internal control (Figure 6B).
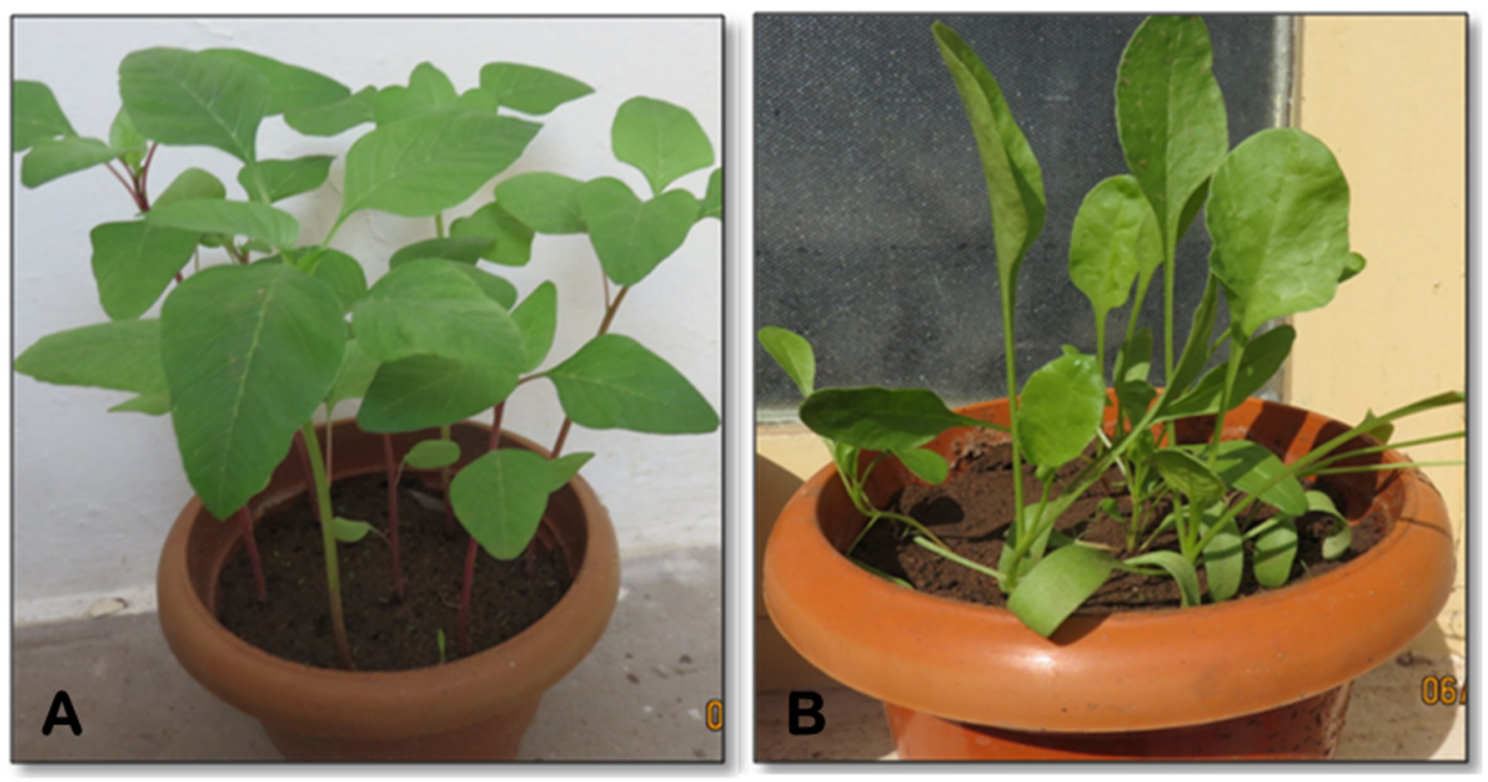

Figure 4. Green leafy vegetables used in the present study. (A) A. tricolor var. tristis; (B) S. oleracea.

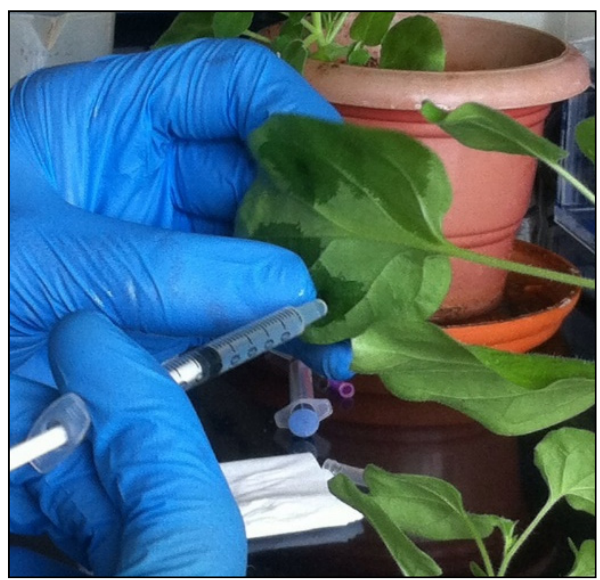

Figure 5. Syringe infiltration; plant leaves were infiltrated using syringe without needle on the abaxial leaf surfaces. 


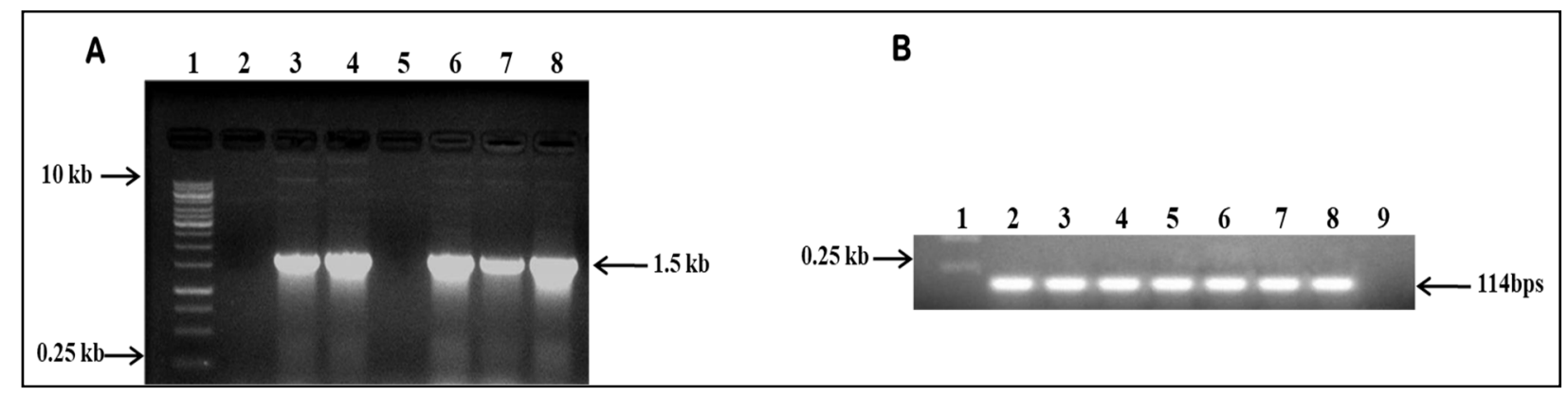

Figure 6. Semiquantitative reverse-transcriptase PCR of GmIFS in infiltrated samples. (A): Lane 1: DNA Marker; lane 2: A. tricolor var. tristis control (wild type); lane 3: A. tricolor var. tristis infiltrated with pEAQ-HT-DEST 3:IFS; lane 4: A. tricolor var. tristis infiltrated with pEarleyGate $102 \mathrm{HA}: I F S$; lane 5: S. oleracea control (wild type); lane 6: S. oleracea infiltrated with pEAQ-HT-DEST 3:IFS; lane 7: S. oleracea infiltrated with pEarleyGate HA 102:IFS; lane 8: positive control (pEAQ-HT-DEST 3:IFS plasmid). (B): $\beta$-Actin internal control.

\subsection{HPLC Detection of Naringenin and Genistein in Infiltrated Samples}

HPLC was performed to determine the presence of naringenin in wild-type $A$. tricolor var. tristis and S. oleracea followed by genistein detection in the infiltrated leaves. The results showed that the naringenin peaks were observed in both the plant species corresponding to that of naringenin standard. Wild-type A. tricolor var. tristis and S. oleracea showed 265.5 and $338.5 \mathrm{nM} / \mathrm{g}$ FW (nanomolar/gram fresh weight) of naringenin in the plant extracts. In the control samples, $S$. oleracea showed higher levels of naringenin content when compared to A. tricolor var. tristis. (Figure 7). Consequently, the naringenin content was also determined in the agroinfiltrated $A$. tricolor var. tristis and S. oleracea with pEarleyGate $102 \mathrm{HA}$ and pEAQ-HT-DEST 3 vectors harboring IFS. As shown in Figure 7, the leaves of $A$. tricolor var. tristis and S. oleracea infiltrated with pEarleyGate 102 HA and pEAQ-HT-DEST 3 showed considerably less concentration of naringenin varying in the range of $65.5-134 \mathrm{nM} / \mathrm{g}$ FW compared to control.

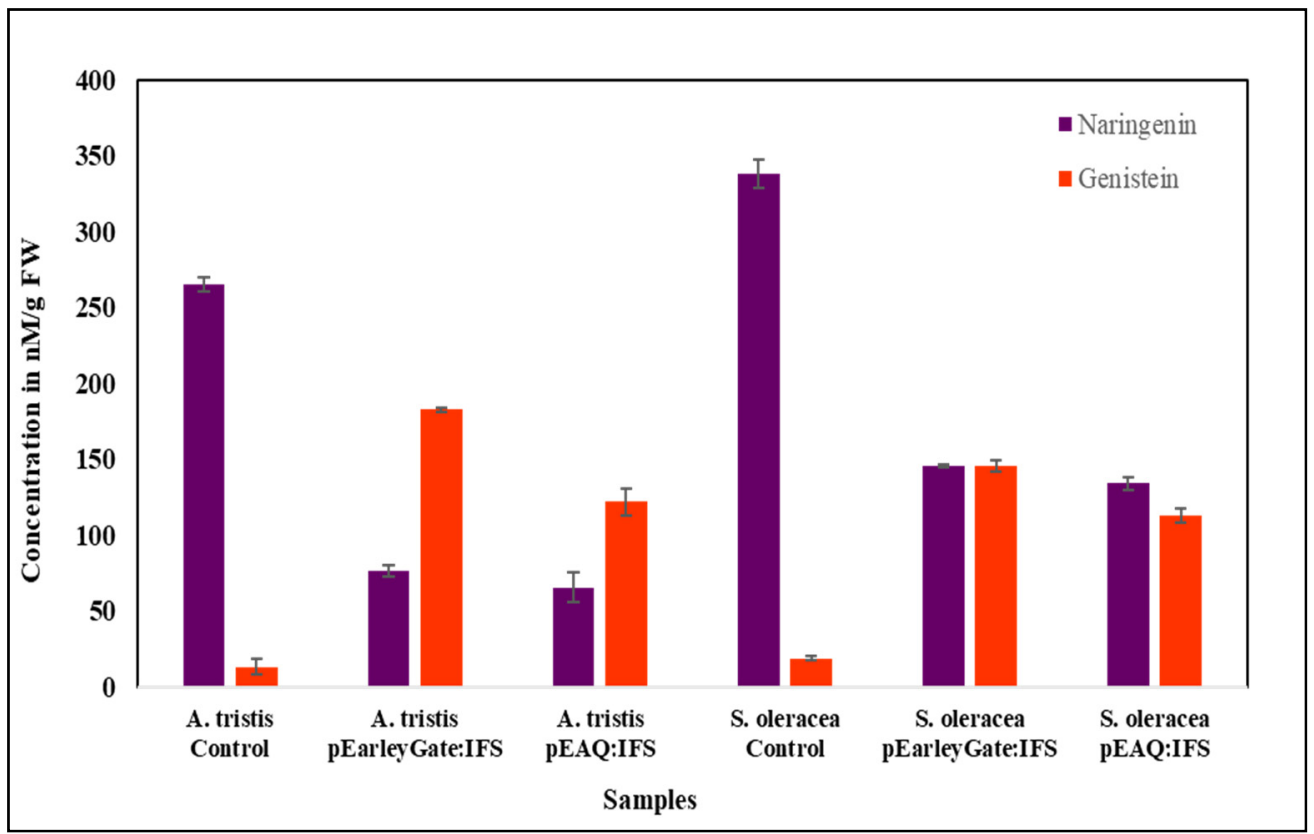

Figure 7. Quantification of naringenin and genistein in control and agroinfiltrated leaf samples of A. tricolor var. tristis and S. oleracea. The HPLC analysis showed the presence of naringenin in control (wild type), and genistein accumulation was observed in agroinfiltrated leaves with pEarleyGate 102 HA:IFS and pEAQ-HT-DEST 3:IFS in both the green leafy vegetables. 
Quantification analysis showed that the leaves infiltrated with GmIFS accumulated comparable amounts of genistein. The peaks in the infiltrated leaves were identified with that of the standard peak of genistein. The wild-type control plants showed a negligible amount of genistein in comparison with the infiltrated leaves. The transiently transformed lines of A. tricolor var. tristis and S. oleracea also showed significant amounts of genistein accumulation with varying concentrations from 113 to $182.6 \mathrm{nM} / \mathrm{g}$ FW (Figure 7). It was observed that almost $65 \%$ of the concentration of naringenin was utilized as substrate for genistein production in A. tricolor var. tristis and about $50 \%$ in case of S. oleracea (Figure 8). The leaves of A. tricolor var. tristis and S. oleracea infiltrated with pEarleyGate $102 \mathrm{HA}$, and pEAQ-HT-DEST 3 harboring IFS showed significant genistein biosynthesis (Figure 8).

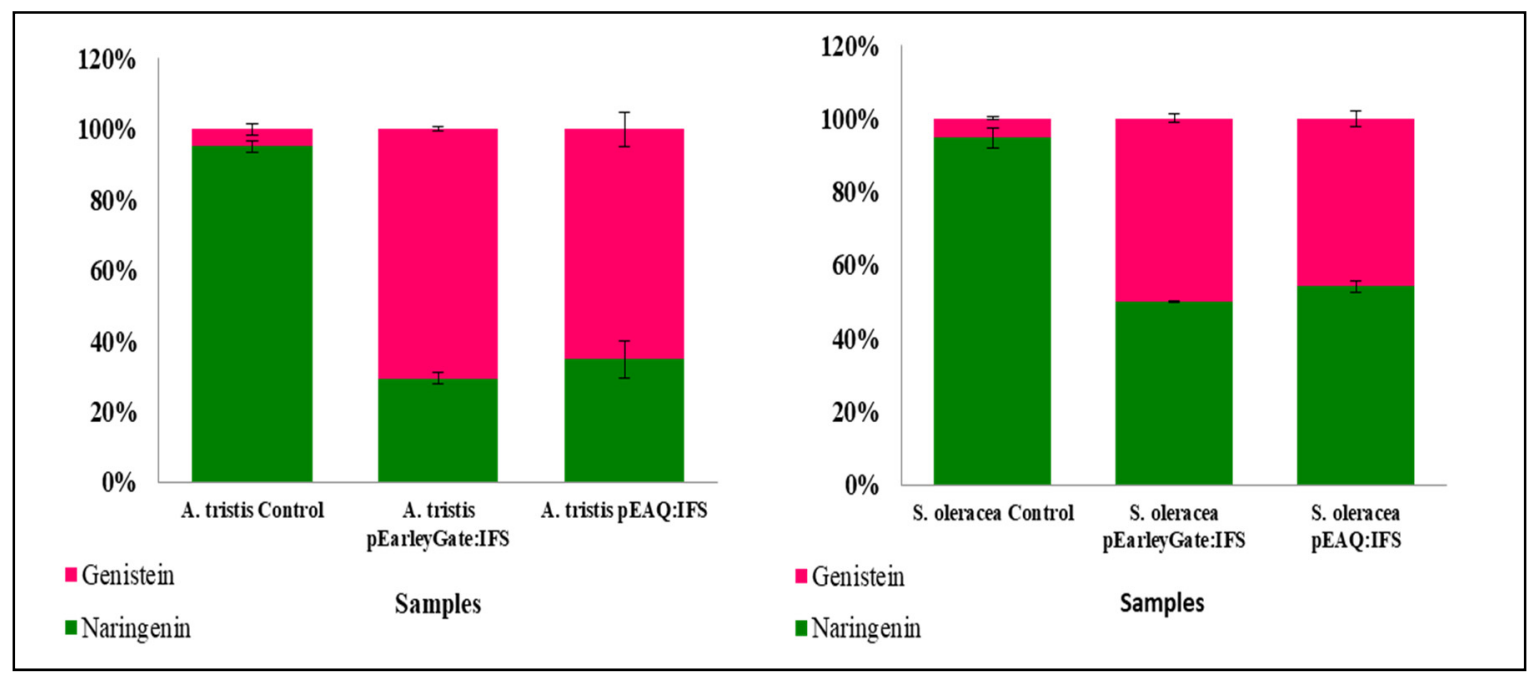

Figure 8. Comparison of genistein accumulation in agroinfiltrated leaves of A. tricolor var. tristis and S. oleracea with pEarleyGate 102 HA:IFS and pEAQ-HT-DEST 3:IFS with wild type (control).

\section{Discussion}

The phenylpropanoid pathway is one of the most studied metabolic frameworks that fulfills several physiological functions necessary for plant growth and development. This pathway involves an array of enzymes that are responsible for the production of different metabolites. IFS is one among them, as it catalyzes the synthesis of isoflavonoids genistein, daidzein from flavonoids naringenin and liquiritigenin, respectively, by an aryl ring migration $[18,49,50]$. As these isoflavonoids are reported to benefit plethora of beneficial activities in humans $[3,8,11,14,18,50,51]$, the present research emphasized on engineering the metabolic pathway by transient expression of GmIFS in non-leguminous plants A.tricolor var. tristis and S. oleracea for the production of genistein which is not normally produced by this species.

Metabolic engineering holds a promising hope for the viable systematization of production of biologically active compounds that are necessary for human health and generation of improved crop varieties involving the redirection of enzymatic reaction(s) in endogenous pathways to synthesize novel products or enrich the existing ones [52-55]. Two approaches employed for the functional gene studies in plants are stable and transient expression. The development of stable transgenic lines by the stable integration of genome of plants is a time-consuming and laborious process. By contrast, the transient expression of heterologous genes in plants has considerable advantages over the stable expression, which is quick and inexpensive for the production of recombinant biopharmaceuticals and valuable metabolites $[26,46]$. Further, this approach could be utilized to study the activity of endogenous and exogenous enzymes in metabolic engineering, which provides insight to understand the mechanisms underlying in the complex gene regulatory and metabolic pathways. The transient gene expression is a rapid, flexible and cost-effective approach 
to study the expression of heterologous genes without the integration of desired gene(s) in the host genome $[56,57]$. The transient expression can be performed either by syringe infiltration or vacuum infiltration [58-60]. The high level of foreign gene expression can be obtained by co-expression of a viral-encoded suppressor of gene silencing which prevents the post-transcriptional gene silencing in the infiltrated tissues $[25,30]$.

Here, we have introduced the GmIFS gene in pEarleyGate HA 102 and pEAQ-HTDEST 3 by gateway cloning [21,61] and mobilized the vectors into A. tumefaciens for agroinfiltration in A. tricolor var. tristis and S. oleracea leaves. Further, the gene expression was confirmed by RT-PCR. The expected amplicon size of $\sim 1.5 \mathrm{~kb}$ corresponding to IFS gene was observed which confirmed the heterologous expression of IFS in the infiltrated leaf samples of $A$. tricolor var. tristis and S. oleracea. The results suggested that the isoflavonoid synthesis is catalyzed by the presence of IFS using the flavonoid intermediates $[18,19,21]$. The earlier reports showed that the stable expression of IFS gene in non-legume plants such as rice, tomato, Arabidopsis, Petunia and onion can produce genistein in transgenic plants $[19,21,62-64]$. The HPLC results revealed that levels of naringenin in the leaf samples of infiltrated A. tricolor var. tristis and S. oleracea decreased significantly compared to that of control, indicating that this compound was utilized by the transformed IFS gene for genistein production. However, the bioactivity of genistein produced transiently in both the plants was not examined. The future work will focus on the elucidation of genistein activity and its production in crop plants. The present study demonstrated that both the plants could be used as hosts for the analysis and pathway engineering of metabolic enzymes. It also depicts that the transient system can be employed to study the function of new vector and validate the expression of both endogenous and exogenous enzymes in metabolic pathways in short time.

\section{Materials and Methods}

\subsection{Plant Materials}

The seeds of A. tricolor var. tristis and S. oleracea were procured from the seed center, Tamil Nadu Agricultural University, Coimbatore, India. These seeds were grown in soil under greenhouse conditions. The plantlets were allowed to grow for $4-5$ weeks.

\subsection{Construction of Plant Expression Vector}

IFS cDNA (Genbank accession number: AF195798) was kindly provided by Dr. Oliver Yu and Dr. Brian Mc Gonigle, Donald Danforth Plant Science Center, USA. The IFS gene was cloned into plant expression vector pEarleyGate 102 HA and pEAQ-HT-DEST 3 by gateway cloning technology (Invitrogen, Carlsbad, CA, USA) as per manufacturer's protocol. The IFS gene was amplified by PCR, and purified PCR products were cloned into entry vector pDONR/Zeo and moved to destination vectors pEarleyGate 102 HA and pEAQ-HTDEST 3, as described previously [21]. The transformed colonies in the destination vector were confirmed by gene-specific PCR and restriction digestion. Subsequently, the plant expression vectors were transformed to A. tumefaciens strain AGL1 by electroporation.

\subsection{Agroinfiltration}

A. tumefaciens strain AGL1 either containing pEarleyGate 102 HA or pEAQ-HT-DEST 3 plasmid harboring IFS gene under the control of CaMV 35S promoter were used for transient expression. The A. tumefaciens cultures were inoculated in $5 \mathrm{~mL}$ of yeast extract, and nutrient broth medium was supplemented with $60 \mathrm{mg} \mathrm{L}^{-1}$ rifampicin and $75 \mathrm{mg} \mathrm{L}^{-1}$ kanamycin and incubated at $28{ }^{\circ} \mathrm{C}$ for 2 days. The grown culture was centrifuged at $5000 \times \mathrm{g} \mathrm{rpm}$ for $15 \mathrm{~min}$ at $4{ }^{\circ} \mathrm{C}$. The supernatants were discarded, and pellets were resuspended in Murashige and Skoog liquid medium. Acetosyringone $(150 \mu \mathrm{M})$ was added to this suspension and incubated at room temperature for $2 \mathrm{~h}$. Agrobacterium suspension was infiltrated into the leaves of $A$. tricolor var. tristis and S. oleracea leaf surfaces using the syringe infiltration technique [65]. The healthy leaves were infiltrated using $1 \mathrm{~mL}$ syringe without the needle on the abaxial leaf surfaces with Agrobacterium suspension to spread 
throughout the leaf lamina and air spaces. The infiltrated plants were maintained at $24{ }^{\circ} \mathrm{C}$ with a $16 \mathrm{~h}$ light cycle for 4 days.

\subsection{RNA Isolation and $c D N A$ Synthesis}

All the materials used for the RNA isolation were treated with diethyl pyrocarbonate (Sigma-Aldrich, Saint Louis, MO, USA). The total RNA was isolated from the infiltrated leaves of $A$. tricolor var. tristis and $S$. oleracea after 4 days post infiltration (dpi). The infiltrated leaves and wild-type leaves were harvested and immediately frozen in liquid nitrogen. The total RNA was isolated from the leaves using total RNA isolation kit (Macherey-Nagel, Düren, Germany). The cDNA was synthesized from the total RNA with random hexamer primer using the M-MuLV reverse transcriptase (M-MuLV RTase) according to the manufacturer's instructions (Fermentas, Waltham, MA, USA). The reaction components used for the cDNA synthesis consisted of $1 \mu \mathrm{g}$ RNA, $0.5 \mu \mathrm{L}$ of random hexamer, nuclease-free water, and the reaction mixture was incubated at $65^{\circ} \mathrm{C}$ for 2 min for denaturation. Immediately, it was kept in ice for $2 \mathrm{~min}$, and the enzyme mixture containing $1 \mathrm{U}$ of M-MuLV RTase, buffer, dNTPs were added and kept at $37{ }^{\circ} \mathrm{C}$ for one hour and then inactivated at $95{ }^{\circ} \mathrm{C}$ for $5 \mathrm{~min}$. The synthesized cDNA was used as template for PCR using the IFS gene specific primers. A reaction mixture containing the PCR master mix, primers and DNA template was prepared as mentioned in Table $1 . \beta$-Actin was used as internal control for the semiquantitative expression analyses.

Table 1. PCR Components and reaction conditions used in the present study.

\begin{tabular}{|c|c|c|c|}
\hline \multicolumn{2}{|l|}{ Reaction Mix } & \multicolumn{2}{|c|}{ Program } \\
\hline Components & Volume $(\mu \mathrm{L})$ & $\begin{array}{c}\text { 1. Initial } \\
\text { Denaturation }\end{array}$ & $94{ }^{\circ} \mathrm{C}$ for $5 \mathrm{~min}$ \\
\hline Emerald AmpR PCR master mix & 10 & 2. Denaturation & $94^{\circ} \mathrm{C}$ for $30 \mathrm{~s}$ \\
\hline Forward primer (10 pM) & 1 & 3. Annealing & $56^{\circ} \mathrm{C}$ for $45 \mathrm{~s}$ \\
\hline Reverse primer (10 pM) & 1 & 4. Extension & $72{ }^{\circ} \mathrm{C}$ for $45 \mathrm{~s}$ \\
\hline Nuclease-free water & 6 & \multicolumn{2}{|c|}{ Step 2-4 repeated 25 cycles } \\
\hline DNA template & 2 & Final Extension & $72{ }^{\circ} \mathrm{C}$ for $10 \mathrm{~min}$ \\
\hline Total & 20 & Final Hold & $4{ }^{\circ} \mathrm{C}$ \\
\hline
\end{tabular}

\subsection{HPLC Detection}

The naringenin standard was obtained from Sigma Aldrich for HPLC analysis. After 4 days post infiltration, infiltrated leaf samples of $A$. tricolor var. tristis and S. oleracea were collected. Wild-type leaves from both the plants were collected and used as control. One gram of fresh leaves was homogenized in HPLC grade methanol. The homogenized mixture was incubated in a concentrator plus vacuum evaporator (Eppendorf, Germany) at $55{ }^{\circ} \mathrm{C}$ for 6-8 h. The dried samples were again extracted in HPLC methanol and filtered through $0.45 \mu \mathrm{m}$ filter. Waters HPLC system equipped with a model 515 HPLC pump, Model 2998 photodiode-array detector and auto sampler was used for analysis. Separations were performed on a $\mathrm{C}_{18}$ column with acetonitrile-water as mobile phase, and the reaction conditions were followed as described previously [21]. Naringenin in the samples was detected at $280 \mathrm{~nm}$ and identified by comparison of their retention times with those of standard.

The genistein standard was obtained from Sigma Aldrich for HPLC detection. Wildtype leaves from A. tricolor var. tristis and S. oleracea were used as controls. After 4 dpi, leaf samples of $A$. tricolor var. tristis and $S$. oleracea leaves were collected, homogenized in HPLC grade methanol and evaporated in concentrator plus vacuum evaporator (Eppendorf, Germany) at $55^{\circ} \mathrm{C}$ for $6-8 \mathrm{~h}$. The obtained dried samples were reconstituted in methanol, and $0.45 \mu \mathrm{L}$ filtration was performed for HPLC analysis. The mobile phase was $80 \%$ methanol programmed at a flow rate of $1.0 \mathrm{~mL} /$ minute [51]. The injection volume was $20 \mu \mathrm{L}$, and the column was maintained at ambient temperature $\left(24-26^{\circ} \mathrm{C}\right)$. Genistein in the samples was detected at $260 \mathrm{~nm}$ and identified by comparison of their retention times with those of standard. 


\subsection{Statistical Analysis}

Two biological replicates were used for HPLC quantification. The results were expressed as mean \pm standard deviation.

\section{Conclusions}

The present study demonstrated that the transient expression of GmIFS gene in A. tricolor var. tristis and S. oleracea can produce the isoflavone genistein from the intermediate naringenin. The transient approach has been utilized to introduce the isoflavone pathway in these green leafy vegetables. To the best of our knowledge, this is the first report on transient expression of GmIFS in the A. tricolor var. tristis and S. oleracea for genistein production. The phenyl propanoid pathway being a complex metabolic pathway can be further explored in detail by the transient approach with infiltration or co-infiltration of multiple genes for complete understanding of the role of other enzymes and substrates involved in biosynthesis of isoflavonoids and other secondary metabolites. This proofof-concept study deciphers light on the production of health-beneficial isoflavones, and other pharmaceutically and nutraceutically relevant compounds by metabolic engineering, which can be employed to produce biofortified crops with better nutritional value for human health.

Author Contributions: Conceptualization, A.M. and S.R.; methodology, A.M. and B.S.; writingoriginal draft preparation, A.M. and B.S.; writing-review and editing, A.M., B.S., A.S. and S.R.; supervision, A.S. and S.R. All authors have read and agreed to the published version of the manuscript.

Funding: The authors would also like to thank UGC-SAP and DST-FIST for the financial support.

Data Availability Statement: The data presented in this study are available on request from the corresponding author.

Acknowledgments: The authors would like to thank Oliver Yu and Brian Mc Gonigle, Donald Danforth Plant Science Center, USA, for providing the Soybean IFS cDNA.

Conflicts of Interest: The authors declare no conflict of interest.

\begin{tabular}{|c|c|}
\hline \multicolumn{2}{|c|}{ Abbreviations } \\
\hline CaMV & Cauliflower mosaic virus \\
\hline cDNA & Complementary deoxyribonucleic acid \\
\hline DNA & Deoxyribonucleic acid \\
\hline dNTP's & Deoxynucleotide triphosphates \\
\hline${ }^{\circ} \mathrm{C}$ & Degrees Celsius \\
\hline FW & Fresh weight \\
\hline HPLC & High-performance liquid chromatography \\
\hline $\mathrm{mg} \mathrm{L}^{-1}$ & Milligram per liter \\
\hline $\mathrm{mL}$ & Milliliter \\
\hline $\mathrm{nm}$ & Nanometer \\
\hline RNA & Ribonucleic acid \\
\hline rpm & Revolutions per minute \\
\hline$\mu \mathrm{L}$ & Microliter \\
\hline$\mu \mathrm{M}$ & Micromolar \\
\hline$\mu$ & Micron \\
\hline $\mathrm{U}$ & Unit \\
\hline
\end{tabular}

\section{References}

1. Yoon, G.-A.; Park, S. Antioxidant action of soy isoflavones on oxidative stress and antioxidant enzyme activities in exercised rats. Nutr. Res. Pract. 2014, 8, 618-624. [CrossRef]

2. Miadoková, E.; Masterová, I.; Vlcková, V.; Dúhová, V.; Tóth, J. Antimutagenic potential of homoisoflavonoids from Muscari racemosum. J. Ethnopharmacol. 2002, 81, 381-386. [CrossRef]

3. Birt, D.F.; Hendrich, S.; Wang, W. Dietary agents in cancer prevention: Flavonoids and isoflavonoids. Pharmacol. Ther. 2001, 90, 157-177. [CrossRef] 
4. Iwasaki, M.; Inoue, M.; Otani, T.; Sasazuki, S.; Kurahashi, N.; Miura, T.; Yamamoto, S.; Tsugane, S. Plasma isoflavone level and subsequent risk of breast cancer among Japanese women: A nested case-control study from the Japan Public Health Center-based prospective study group. J. Clin. Oncol. 2008, 26, 1677-1683. [CrossRef] [PubMed]

5. Scarpato, R.; Paganucci, L.; Bertoli, A.; Fiore, L.; Pistelli, L.; Federico, G. Licoflavone C attenuates the genotoxicity of cancer drugs in human peripheral lymphocytes. Phytother. Res. 2008, 22, 1650-1654. [CrossRef]

6. Popova, P.; Zarev, Y.; Mihaylova, R.; Momekov, G.; Ionkova, I. Antiproliferative activity of extract from in vitro callus cultures of Astragalus vesicarius ssp. carniolicus (A. Kern.) Chater. Pharmacia 2021, 68, 217. [CrossRef]

7. Kohen, F.; Gayer, B.; Kulik, T.; Frydman, V.; Nevo, N.; Katzburg, S.; Limor, R.; Sharon, O.; Stern, N.; Somjen, D. Synthesis and Evaluation of the Antiproliferative Activities of Derivatives of Carboxyalkyl Isoflavones linked to N-t-Boc-hexylenediamine. J. Med. Chem. 2007, 50, 6405-6410. [CrossRef]

8. Foudah, A.; Abdel-Kader, A. Isoflavonoids, Flavonoids_From Biosynthesis to Human Health; Justino, G.C., Ed.; IntechOpen: London, UK, 2017. [CrossRef]

9. Ryan-Borchers, T.A.; Park, J.S.; Chew, B.P.; McGuire, M.K.; Fournier, L.R.; Beerman, K.A. Soy isoflavones modulate immune function in healthy postmenopausal women. Am. J. Clin. Nutr. 2006, 83, 1118-1125. [CrossRef]

10. Reiter, R.J.; Paredes, S.D.; Korkmaz, A.; Jou, M.-J.; Tan, D.-X. Melatonin combats molecular terrorism at the mitochondrial level. Interdiscip. Toxicol. 2008, 1, 137-149. [CrossRef]

11. Dixon, R.A.; Sumner, L.W. Legume natural products: Understanding and manipulating complex pathways for human and animal health. Plant Physiol. 2003, 131, 878-885. [CrossRef] [PubMed]

12. Malla, A.; Ramalingam, S. Health Perspectives of an Isoflavonoid Genistein and its Quantification in Economically Important Plants. In Role of Materials Science in Food Bioengineering; Grumezescu, A.M., Holban, A.M., Eds.; Academic Press: Cambridge, MA, USA, 2018; Chapter 11; pp. 353-379. [CrossRef]

13. Bezek, S.; Ujházy, E.; Mach, M.; Navarová, J.; Dubovický, M. Developmental origin of chronic diseases: Toxicological implication. Interdiscip. Toxicol. 2008, 1, 29-31. [CrossRef] [PubMed]

14. Miadoková, E. Isoflavonoids-an overview of their biological activities and potential health benefits. Interdiscip. Toxicol. 2009, 2, 211-218. [CrossRef] [PubMed]

15. Sharma, V.; Ramawat, K.G. Isoflavonoids. In Natural Products: Phytochemistry, Botany and Metabolism of Alkaloids, Phenolics and Terpenes; Ramawat, K.G., Mérillon, J.-M., Eds.; Springer: Berlin/Heidelberg, Germany, 2013; pp. 1849-1865. [CrossRef]

16. Sabudak, T.; Guler, N. Trifolium L.-A review on its phytochemical and pharmacological profile. Phytother. Res. 2009, 23, 439-446. [CrossRef]

17. Ørgaard, A.; Jensen, L. The effects of soy isoflavones on obesity. Exp. Biol. Med. 2008, 233, 1066-1080. [CrossRef]

18. Jung, W.; Yu, O.; Lau, S.-M.C.; O’Keefe, D.P.; Odell, J.; Fader, G.; McGonigle, B. Identification and expression of isoflavone synthase, the key enzyme for biosynthesis of isoflavones in legumes. Nat. Biotechnol. 2000, 18, 208-212. [CrossRef] [PubMed]

19. Sreevidya, V.; Srinivasa Rao, C.; Sullia, S.; Ladha, J.K.; Reddy, P.M. Metabolic engineering of rice with soybean isoflavone synthase for promoting nodulation gene expression in rhizobia. J. Exp. Bot. 2006, 57, 1957-1969. [CrossRef] [PubMed]

20. Cheng, H.; Wang, J.; Chu, S.; Yan, H.-L.; Yu, D. Diversifying Selection on Flavanone 3-Hydroxylase and Isoflavone Synthase Genes in Cultivated Soybean and Its Wild Progenitors. PLoS ONE 2013, 8, e54154. [CrossRef]

21. Malla, A.; Shanmugaraj, B.; Srinivasan, B.; Sharma, A.; Ramalingam, S. Metabolic Engineering of Isoflavonoid Biosynthesis by Expressing Glycine max Isoflavone Synthase in Allium cepa L. for Genistein Production. Plants 2021, 10, 52. [CrossRef]

22. Bevan, M. Binary Agrobacterium vectors for plant transformation. Nucleic Acids Res. 1984, 12, 8711-8721. [CrossRef] [PubMed]

23. Gelvin, S.B. Agrobacterium-Mediated Plant Transformation: The Biology behind the "Gene-Jockeying" Tool. Microbiol. Mol. Biol. Rev. 2003, 67, 16-37. [CrossRef]

24. Sainsbury, F.; Lomonossoff, G.P. Transient expressions of synthetic biology in plants. Curr. Opin. Plant Biol. 2014, 19, 1-7. [CrossRef]

25. Yamamoto, T.; Hoshikawa, K.; Ezura, K.; Okazawa, R.; Fujita, S.; Takaoka, M.; Mason, H.S.; Ezura, H.; Miura, K. Improvement of the transient expression system for production of recombinant proteins in plants. Sci. Rep. 2018, 8, 4755. [CrossRef]

26. Tyurin, A.A.; Suhorukova, A.V.; Kabardaeva, K.V.; Goldenkova-Pavlova, I.V. Transient Gene Expression is an Effective Experimental Tool for the Research into the Fine Mechanisms of Plant Gene Function: Advantages, Limitations, and Solutions. Plants 2020, 9, 1187. [CrossRef]

27. Shanmugaraj, B.; Bulaon, C.J.I.; Phoolcharoen, W. Plant Molecular Farming: A Viable Platform for Recombinant Biopharmaceutical Production. Plants 2020, 9, 842. [CrossRef]

28. Shanmugaraj, B.; Ramalingam, S. Plant Expression Platform for the Production of Recombinant Pharmaceutical Proteins. Austin J. Biotechnol. Bioeng. 2014, 1, 4 .

29. Mardanova, E.S.; Blokhina, E.A.; Tsybalova, L.M.; Peyret, H.; Lomonossoff, G.P.; Ravin, N.V. Efficient Transient Expression of Recombinant Proteins in Plants by the Novel pEff Vector Based on the Genome of Potato Virus X. Front. Plant Sci. 2017, 8. [CrossRef] [PubMed]

30. Voinnet, O.; Rivas, S.; Mestre, P.; Baulcombe, D. An enhanced transient expression system in plants based on suppression of gene silencing by the p19 protein of tomato bushy stunt virus. Plant J. 2003, 33, 949-956. [CrossRef] [PubMed]

31. Stephenson, M.J.; Reed, J.; Brouwer, B.; Osbourn, A. Transient Expression in Nicotiana Benthamiana Leaves for Triterpene Production at a Preparative Scale. J. Vis. Exp. 2018, 58169. [CrossRef] [PubMed] 
32. Burnett, M.J.B.; Burnett, A.C. Therapeutic recombinant protein production in plants: Challenges and opportunities. Plants People Planet 2020, 2, 121-132. [CrossRef]

33. Sathish, S.; Preethy, K.S.; Venkatesh, R.; Sathishkumar, R. Rapid enhancement of $\alpha$-tocopherol content in Nicotiana benthamiana by transient expression of Arabidopsis thaliana Tocopherol cyclase and Homogentisate phytyl transferase genes. 3 Biotech 2018, 8, 485. [CrossRef] [PubMed]

34. Randhawa, M.A.; Khan, A.A.; Javed, M.S.; Sajid, M.W. Green Leafy Vegetables: A Health Promoting Source. In Handbook of Fertility; Watson, R.R., Ed.; Academic Press: San Diego, CA, USA, 2015; Chapter 18; pp. 205-220. [CrossRef]

35. Sharma, H.; Rawal, A. Health Security in Ethnic Communities through Nutraceutical Leafy Vegetables. J. Environ. Res. Dev. 2013, 7, 1423-1429.

36. Tarwadi, K.; Agte, V. Potential of commonly consumed green leafy vegetables for their antioxidant capacity and its linkage with the micronutrient profile. Int. J. Food Sci. Nutr. 2003, 54, 417-425. [CrossRef] [PubMed]

37. Gupta, S.; Prakash, J. Studies on Indian Green Leafy Vegetables for Their Antioxidant Activity. Plant Foods Hum. Nutr. 2009, 64, 39-45. [CrossRef] [PubMed]

38. Shanmugaraj, B.M.; Ramamoorthy, D.; Aziz, R.; Malla, A.; Ramalingam, S. Assessment of free radical scavenging activities of leaves and stem fractions of green leafy vegetables. Afr. J. Pharm. Pharmacol. 2014, 8, 1138-1145.

39. Bhat, R.S.; Al-Daihan, S. Phytochemical constituents and antibacterial activity of some green leafy vegetables. Asian Pac. J. Trop. Biomed. 2014, 4, 189-193. [CrossRef]

40. Khanam, U.K.S.; Oba, S.; Yanase, E.; Murakami, Y. Phenolic acids, flavonoids and total antioxidant capacity of selected leafy vegetables. J. Funct. Foods 2012, 4, 979-987. [CrossRef]

41. Sarker, U.; Hossain, M.M.; Oba, S. Nutritional and antioxidant components and antioxidant capacity in green morph Amaranthus leafy vegetable. Sci. Rep. 2020, 10, 1336. [CrossRef] [PubMed]

42. Murugan, S.B.; Reshma, A.; Deepika, R.; Balamurugan, S.; Sathishkumar, R. Antioxidant capacities of Amaranthus tristis and Alternanthera sessilis: A comparative study. J. Med. Plants Res. 2013, 7, 2230-2235.

43. Murugan, S.B.; Sathishkumar, R. Establishment of High Frequency Callus induction and Genetic Transformation in Neglected Leafy Vegetable Amaranthus trisis. Austin J. Biotechnol. Bioeng. 2016, 3, 1058.

44. Chin, D.P.; Bao, J.H.; Mii, M. Transgenic spinach plants produced by Agrobacterium-mediated method based on the low temperature-dependent high plant regeneration ability of leaf explants. Plant Biotechnol. 2009, 26, 243-248. [CrossRef]

45. Earley, K.W.; Haag, J.R.; Pontes, O.; Opper, K.; Juehne, T.; Song, K.; Pikaard, C.S. Gateway-compatible vectors for plant functional genomics and proteomics. Plant J. 2006, 45, 616-629. [CrossRef]

46. Sainsbury, F.; Thuenemann, E.C.; Lomonossoff, G.P. pEAQ: Versatile expression vectors for easy and quick transient expression of heterologous proteins in plants. Plant Biotechnol. J. 2009, 7, 682-693. [CrossRef]

47. Ku, Y.-S.; Ng, M.-S.; Cheng, S.-S.; Lo, A.W.-Y.; Xiao, Z.; Shin, T.-S.; Chung, G.; Lam, H.-M. Understanding the Composition, Biosynthesis, Accumulation and Transport of Flavonoids in Crops for the Promotion of Crops as Healthy Sources of Flavonoids for Human Consumption. Nutrients 2020, 12, 1717. [CrossRef]

48. Gehl, J. Electroporation: Theory and methods, perspectives for drug delivery, gene therapy and research. Acta Physiol. Scand. 2003, 177, 437-447. [CrossRef]

49. Biała, W.; Jasiński, M. The Phenylpropanoid Case-It Is Transport That Matters. Front. Plant Sci. 2018, 9. [CrossRef] [PubMed]

50. García-Calderón, M.; Pérez-Delgado, C.M.; Palove-Balang, P.; Betti, M.; Márquez, A.J. Flavonoids and Isoflavonoids Biosynthesis in the Model Legume Lotus japonicus; Connections to Nitrogen Metabolism and Photorespiration. Plants 2020, 9, 774. [CrossRef] [PubMed]

51. Orhan, I.; Özçelik, B.; Kartal, M.; Aslan, S.; Sener, B.; Özgüven, M. Quantification of daidzein, genistein and fatty acids in soybeans and soy sprouts, and some bioactivity studies. Acta Biol. Crac. Ser. Bot. 2007, 49, 61-68.

52. Kumar, A. Metabolic Engineering in Plants. In Plant Biology and Biotechnology: Plant Genomics and Biotechnology; Bahadur, B., Venkat Rajam, M., Sahijram, L., Krishnamurthy, K.V., Eds.; Springer: New Delhi, India, 2015; Volume II, pp. 517-526. [CrossRef]

53. Lu, X.; Tang, K.; Li, P. Plant Metabolic Engineering Strategies for the Production of Pharmaceutical Terpenoids. Front. Plant Sci. 2016, 7, 1647. [CrossRef]

54. Sangwan, N.S.; Jadaun, J.S.; Tripathi, S.; Mishra, B.; Narnoliya, L.K.; Sangwan, R.S. Plant Metabolic Engineering. In Omics Technologies and Bio-Engineering; Barh, D., Azevedo, V., Eds.; Academic Press: Cambridge, MA, USA, 2018; Chapter 9; pp. 143-175. [CrossRef]

55. Chownk, M.; Thakur, K.; Yadav, S.K. Retrospect and prospects of plant metabolic engineering. J. Plant Biochem. Biotechnol. 2019, 28, 1-13. [CrossRef]

56. Kapila, J.; De Rycke, R.; Van Montagu, M.; Angenon, G. An Agrobacterium-mediated transient gene expression system for intact leaves. Plant Sci. 1997, 122, 101-108. [CrossRef]

57. Fischer, R.; Emans, N. Molecular farming of pharmaceutical proteins. Transgenic Res. 2000, 9, 279-299. [CrossRef]

58. Joh, L.D.; Wroblewski, T.; Ewing, N.N.; VanderGheynst, J.S. High-level transient expression of recombinant protein in lettuce. Biotechnol. Bioeng. 2005, 91, 861-871. [CrossRef]

59. Bhaskar, P.B.; Venkateshwaran, M.; Wu, L.; Ané, J.-M.; Jiang, J. Agrobacterium-Mediated Transient Gene Expression and Silencing: A Rapid Tool for Functional Gene Assay in Potato. PLoS ONE 2009, 4, e5812. [CrossRef] 
60. Mooney, B.C.; Graciet, E. A simple and efficient Agrobacterium-mediated transient expression system to dissect molecular processes in Brassica rapa and Brassica napus. Plant Direct 2020, 4, e00237. [CrossRef] [PubMed]

61. Ashwini, M.; Murugan, S.B.; Balamurugan, S.; Sathishkumar, R. Advances in molecular cloning. Mol. Biol. 2016, 50, 1-6. [CrossRef]

62. Liu, C.-J.; Blount, J.W.; Steele, C.L.; Dixon, R.A. Bottlenecks for metabolic engineering of isoflavone glycoconjugates in Arabidopsis Proc. Natl. Acad. Sci. USA 2002, 99, 14578-14583. [CrossRef] [PubMed]

63. Liu, R.; Hu, Y.; Li, J.; Lin, Z. Production of soybean isoflavone genistein in non-legume plants via genetically modified secondary metabolism pathway. Metab. Eng. 2007, 9, 1-7. [CrossRef] [PubMed]

64. Shih, C.-H.; Chen, Y.; Wang, M.; Chu, I.K.; Lo, C. Accumulation of Isoflavone Genistin in Transgenic Tomato Plants Overexpressing a Soybean Isoflavone Synthase Gene. J. Agric. Food Chem. 2008, 56, 5655-5661. [CrossRef]

65. D' Doust, M.A.; Lavoie, P.O.; Couture, M.M.; Trépanier, S.; Guay, J.M.; Dargis, M.; Mongrand, S.; Landry, N.; Ward, B.J.; Vézina, L.P. Influenza virus-like particles produced by transient expression in Nicotiana benthamiana induce a protective immune response against a lethal viral challenge in mice. Plant Biotechnol. J. 2008, 6, 930-940. [CrossRef] 